\title{
Recommended content of referral letters from general practitioners to specialised mental health care: a qualitative multi-perspective study
}

\author{
Miriam Hartveit ${ }^{1,2^{*}}$, Olav Thorsen ${ }^{2}$, Eva Biringer ${ }^{1,3}$, Kris Vanhaecht $^{1,4}$, Benedicte Carlsen ${ }^{5}$ and Aslak Aslaksen ${ }^{6,7}$
}

\begin{abstract}
Background: In most Western countries, the referral letter forms the basis for establishing the priority of patients for specialised health care and for the coordination of care between the services. To be able to define the quality of referral letters, the potential impact of the quality on the organisation of care, and to improve the quality of the letters, we need a multidimensional definition of the ideal content. The study's aim was to explore what information is seen as most important and should be included in referral letters from primary care to specialised mental health care to facilitate prioritisation and planning of treatment and follow-up of the patients.

Methods: Based on purposive sampling, four mixed discussion groups, which included general practitioners, mental health nurses from primary health care, psychiatrists and psychologists from specialised mental health care, managers and patient representatives, were formed; they were asked to identify the information they considered important in a mental health referral letter. In line with the Delphi technique, the importance of the themes was later individually rated by the participants. The study was conducted within The Western Norway Regional Health Authority.
\end{abstract}

Results: The four groups identified 174 information themes. After excluding themes that were assessed as duplicates, replaceable or less important, 40 themes were suggested, organised in seven units. A set of check-off points of essential information is recommended as an introduction in the referral letter.

Conclusion: Compared with general guidelines and guidelines for somatic care, the results of this study suggest that the referral letter to specialised mental health care should have a larger emphasis on the overall treatment plan, on the specific role of specialised health care in the continuum of care, and on patient involvement. Further research should evaluate the validity of these findings for other patient groups in need of integrated care and investigate how the quality of referral letters affects patient-related and organisational outcomes.

Trial Registration: Trial Registration number: NCT01374035

Keywords: Referral and consultation, Mental health, Health services, General practice, Group interview

\section{Background}

Patients suffering from mental disorders are one of the largest patient groups worldwide and constitute a significant contribution to the global burden of disease [1]. Provision of equal healthcare to those with equal needs (horizontal equity) and sufficient accessibility to specialised mental

\footnotetext{
* Correspondence: miriam.hartveit@helse-fonna.no

${ }^{1}$ Research Network on Integrated Health Care in Western Norway, Helse

Fonna HF, Valen Hospital, N-5451, Haugesund, Valen, Norway

${ }^{2}$ Department of Public Health and Primary Health Care, Faculty of Medicine

and Dentistry, University of Bergen, Bergen, Norway

Full list of author information is available at the end of the article
}

health care is therefore important not only to the individual patients and their relatives, but also to the society $[1,2]$. Within a health care system where specialist health care is a limited recourse, it is of great importance that the patients most in need are prioritised. In Norway, as in many Western countries, the prioritisation is conducted in two steps: first, a General Practitioner (GP) decides if a patient should be referred; and second, a specialist decides if and when the patient should receive specialist health care. For both steps, the GP needs to know what information the referral letter should include [3]. However, studies on the 
content of referral letters suggest that they lack important information [4-6]. The consequences of low quality referral letters are to a large degree unknown, but a positive correlation has been found between the content of referral letters and the specialists' confidence that they have enough information to make the correct priority for patients receiving cancer care [7]. A recent study by Holman et al. revealed a fair inter-rater reliability between specialists prioritisation of patients based on referral letters within mental health care [8], indicating a risk of low horizontal equity. Both studies suggest defining guidelines for the content of referral letters as one strategy to improve the process of prioritisation $[7,8]$.

During recent decades, suggestions as to what information referral letters ideally should include have been put forward, but variable quality of referral letters seems to be persistent $[5,6]$. According to Øvretveit's definition, quality in healthcare involves three perspectives: professional, patient, and management [9]. Guidelines, for instance for the ideal content of referral letters, should be defined by consensus of representative health professionals, patients, and managers. Studies revealing a discrepancy within the professional perspective regarding the appropriate content of referral letters indicate that both GPs and hospital specialists should be represented [10-12]. However, existing studies on the quality of referral letters are often based on a standard determined and defined by health personnel alone or only by hospital specialists $[4,6]$. Another barrier for improving the content of referral letters could be the extent and numbers of different guidelines that GPs are expected to comply with, if all specialities define their own local guidelines. By contrast, using scientific methods to define one standard of the most important information by consensus between the involved parties is in accordance with effective quality improvement $[9,13,14]$.

By legislation, the prioritisation of patients in Norway is based on an assessment of (i) the condition and its influence on quality of life, (ii) the expected effect of recommended interventions (utility), and (iii) the costeffectiveness of suggested intervention $[15,16]$. "The good referral letter" is a Norwegian recommended guideline for the content of referral letters [17]. It is a general form for both somatic and psychiatric care, and includes the patient's personal information, information on the referring doctor, special information (allergy), diagnosis, expected treatment, relevant information on the patient's situation and condition, the level of pain or problems, and the degree of urgency [17]. It does not focus on patient experiences as suggested in mental health referral letters [18].

To be able to explore the consequences of the quality of referral letters and to improve the quality of referral letters, we need a valid definition of the most important information it must include [13,19]. The study is an example of a procedure for the first two steps in quality improvement: select the target area and define recommended practice (see Table 1 "The first two steps in quality improvement"). The aim of the present study was to identify what a referral letter to specialised mental health care should include to provide the necessary information to correctly and sufficiently prioritise and plan treatment and follow-up of patients, as perceived by patients, health professionals and managers.

\section{Methods}

The study consisted of two steps. First, structured group interviews [20] with mixed groups representing patients, health professionals and managers were conducted. Second, the Delphi method (a postal questionnaire method where suggested items are reviewed by the same participants for a second rating) [20] was used to prioritise the suggested themes from the group interviews. The study was conducted within the Western Norway Regional Health Authority (population: 1 million). We used purposive sampling [20] based on Øvretveit's defined perspectives of quality in health care [9]. Health professionals from both primary health care (GPs and mental health nurses) and specialised mental health care (psychiatrists and trained psychologists) represented the professional perspective. Participants were enrolled by persons or organisations external to the study based on their experience and interest in the subject. Patient representatives and GPs were enrolled by their local organisations, while managers, mental health nurses in primary care and specialists were suggested by their managers. Participation was based on written informed consent according to the Helsinki Declaration [21]. The study was presented and accepted by the Norwegian Social Science Data Service and the National Committee for Medical and Health Research Ethics.

\section{Step 1: group interviews}

The group interviews were conducted as consensus development panels, as defined by Bowling [20]. Four groups were formed and interviewed once in a nearby health care centre. There were 19 participants, whereas twelve were men. Nine of the participants were health professionals within primary or specialized mental health care, four patient representatives and six were managers. In addition to their professional titles, many had experience in several areas, e.g. managers or patient representatives that also have a health professional background. They were all experienced; almost half had more than 15 years of experience in their present position. The timeframe for an interview was predefined to last two to three hours. The interviews started with a short presentation of the participants, the study, and the purpose of referral letters. By brainstorming, participants wrote ideas 
Table 1 The first two steps in quality improvement

\begin{tabular}{|c|c|}
\hline Theory based steps & In this case \\
\hline \multicolumn{2}{|l|}{ 1. Select target area } \\
\hline Frequency & $\begin{array}{l}\text { Large patient population [1], referral letters used whenever need for specialised } \\
\text { health care. }\end{array}$ \\
\hline Importance & Large suffering, large impact on society [1] \\
\hline Complexity & Many stakeholders, inter-organisational \\
\hline $\begin{array}{l}\text { Insufficiently effective, efficient, accessible, acceptable/patient- } \\
\text { centred, equitable, and/or safe care [28] }\end{array}$ & Risk of incorrect prioritisation of patients and inappropriate care $[7,8]$ \\
\hline Expected improvement potential [13] & $\begin{array}{l}\text { Studies reveal that referral letters in general and within mental health care lack } \\
\text { important information [4-6] }\end{array}$ \\
\hline \multicolumn{2}{|l|}{ 2. Determine/define recommended practice } \\
\hline Explore existing knowledge [13] & $\begin{array}{l}\text { Literature review revealed no evidence-based recommended standard for content } \\
\text { of referral letters to specialised mental health care }\end{array}$ \\
\hline If not sufficient knowledge: Define recommended practice & Structured group interview using the method Language Processing [20] \\
\hline A. Involve valid perspectives [9]: & Including: \\
\hline Professional & $\begin{array}{l}\text { Health professionals from primary care (GPs and mental health nurses) and from } \\
\text { specialist mental health care (psychiatrist and trained psychologists) }\end{array}$ \\
\hline Patient/client & Patient representatives from Mental Health Patient Organisation \\
\hline Organisational & Operating managers within specialist mental health care. \\
\hline B. Make feasible [13] & $\begin{array}{l}\text { Delphi process to determine the most important content. Exclusion of themes where } \\
\text { less than } 75 \% \text { of participants have rated them as highly important [22]. }\end{array}$ \\
\hline
\end{tabular}

The theoretical framework for the method employed in this study.

on post-it notes to the question "What information do you think is important that the specialised mental health care receive in a referral letter?". The ideas (information themes) were collected and reviewed in the group to ensure a common understanding of each theme. The participants were then encouraged to take part in open discussion on issues relevant to good referral letters and were given the opportunity to write down additional themes. At the end, the groups analysed their themes by grouping them and creating a heading for each group of themes. The interview was led by a senior mental health researcher (E.B.); while the categorising of themes was led by the group itself and was observed by a researcher (M.H.). One week after the second interview, the participants in the first two groups were phoned by a researcher and asked if they had additional themes. This part of the process did not result in any new themes and was discontinued. The input from the four groups was combined and analysed together by two researchers (M.H. and O.T.). First, inter-group duplicates were removed. Then, themes with equivalent meanings were made into single themes. Finally, by consensus, new common headings were developed based on the groups' headings with the associated themes by two internal researchers (A.A. and M.H.) and one external researcher (O.H.). These headings were reviewed and approved by the researcher leading the group interviews (E.B.).

\section{Step 2: individual rating}

Within the Delphi technique, the suggested information requirements that had been analysed and organised into the new headings and themes were sent to the participants [20]. They were asked to individually rate each theme's importance on a scale from 0 (= "not important/ irrelevant") to 5 (= "extremely important/cardinal"). With the occurrence of a perceived overlap of themes, the participants were to place a " 0 " by the redundant theme and mark it with the number of the theme that should replace it. We started the analysis of the individual ratings by excluding the theme that the most participants considered replaceable and marking the theme that replaced it. We then excluded the theme that was seen as second most replaceable by the participants, and so on. Themes that were marked as "replacers" were not excluded. Those assessed as replaceable by only one or two participants were not excluded. Finally, we used a predefined cut-off limit of $75 \%$ or more of the participants scoring the themes at 4 or 5 , as did Deneckere and colleagues [22]. Only the themes rated as most important or second most important by $75 \%$ or more of the participants were included.

\section{Results}

Four group interviews were conducted with a total of 19 participants Seventeen completed the individual ratings using the questionnaire. The four groups suggested 174 themes. After excluding inter group duplicates and themes assessed as replaceable, 71 themes were left. Once we excluded themes that less than $75 \%$ of the respondents had rated as important ( 4 or 5 on the scale), we had a list of 40 themes that the participants considered as 
the most important information in a referral letter to specialised mental health care. The process is illustrated in Figure 1 "The reduction process". The groups suggested from five to eleven headings. The four sets of headings with the suggested themes were analysed by three individual researchers. By consensus, seven headings were found to adequately cover the four sets:

- $>$ Personal information and contact information.

- $>$ Important introductory information (check-off points).

- $>$ Case history and social situation.

- $>$ Present state and results.

- $\quad>$ Past and on-going treatment efforts, involved professional network.

- $>$ The patient's assessment.

- $>$ Reason for the referral.

The main findings are that referral letters to specialised mental health care should include the overall plan for care, the involved services and interventions, and the patient's preferences and goals as well as the regular information usually found in referral letters. An introductory section to the referral letter with check-off points about essential information was also suggested. The recommended information for a referral letter to specialised mental health care for adults, including the check-off points, is shown in Figure 2 "Suggested content of referral letters to Specialised Mental Health Care".

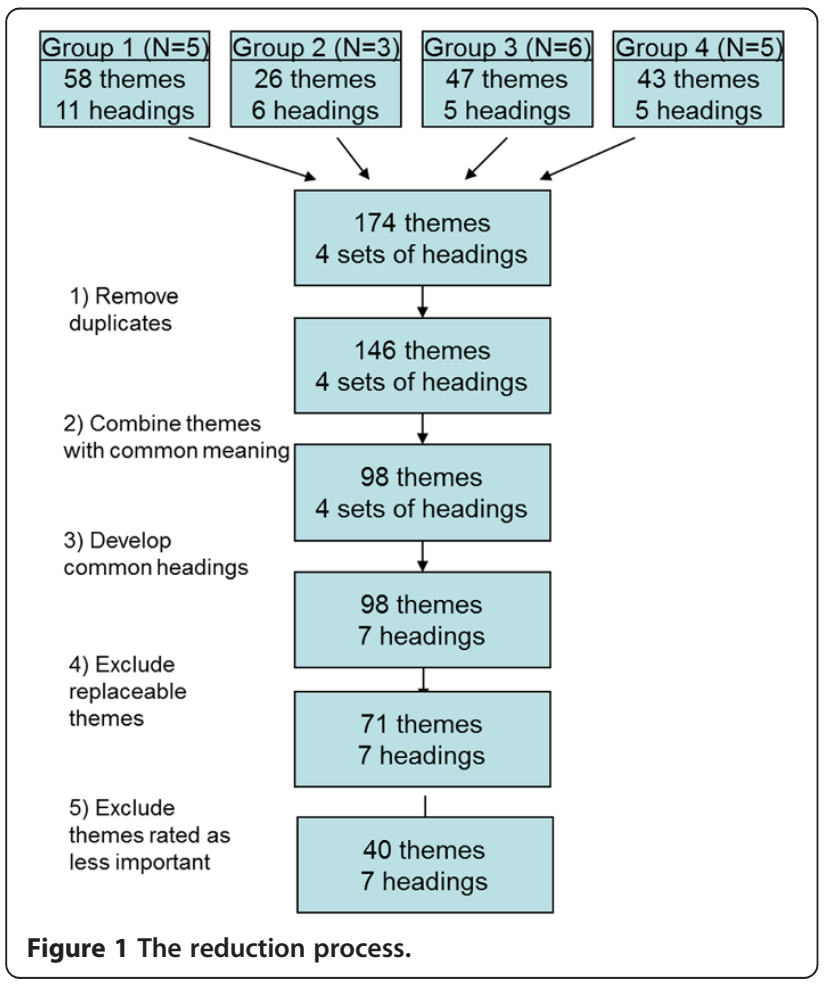

\section{Discussion}

The findings of the study identify referral letter information seen as important when referring a patient to specialised mental health care. The recommendations from the multi-perspective groups suggests a stronger emphasis on information about the planned integrated care, the specialist health care provider's role in it, and on the patient's involvement compared with "standard" referral letter forms. An introduction with seven check-off points on essential information also evolved during this study.

In contrast to many other efforts to define a standard for content of referral letters, we chose to invite the patients, the management and the professionals to give their perspective into the referral letter evaluation process. Since the referral letter is a communication means mainly between GPs and specialists, it can be argued that doctors are the only ones who are able to discern the type of information it should contain. However, there is increased focus on the importance of the patient perspective to aid in understanding and improving the quality of health care $[9,23]$. Another important aspect is health care management including knowledge about economic and legal opportunities and boundaries. Studies showing disagreement on appropriateness of referrals and the content of referral letters between stakeholders in the referral process support a comprehensive sampling [11,12]. We argue that the inclusion of all three perspectives gives a fuller description of the health care process and as such increases the validity of the results.

The groups were mixed to increase the richness of the data. Yet, there is the risk that the asymmetrical distribution of power that can be found within health care services could be maintained in the groups. To offset this possible asymmetry, and based on advice from patient representatives, we aimed at including at least two patient representatives in each group, but because of mitigating circumstances, achieved this in only two of the four groups. However, the large amount of input from the patient representatives gives us reason to believe that the effort to create a balance of power in the groups was successful. The definition of quality in health care, which forms the basis for the sampling method, is valid for all health care and therefore strengthens the generalisability of the findings. However, legislation, tradition and culture can affect which information is seen as important in a referral letter. The participants in this study were selected for their extensive experience and interest in the subject, and though this gave indepth insight into the topic, it can also at times be a barrier to innovative ideas and criticism within the topic. Another limitation in the study can be the type of services and professions represented in the sample. Other services such as unemployment agencies or social services may have information that could alter the results regarding 


\section{Personal information and contact information}

- Personal information that ensures correct identity and contact information, inclusive of phone numbers to relatives

- Patient data: Social security number, place of residence

- Information on the referring doctor, and contact information: phone number, where to reach him/her.

- If the referring doctor is not the patient's GP/family doctor, who is?

Important introductory information (check-off points)

- Is there an imminent danger for the need of compulsory care?

- Is the patient suicidal?

- Is the patient a threat to others?

- Is there an emergency situation?

- Is the patient responsible for the care of children?

- Do you suspect severe illness/psychosis?

- Does the patient have a drug problem or addiction?

$\begin{array}{ll}\square \text { Yes } & \square \text { No } \\ \square \text { Yes } & \square \text { No } \\ \square \text { Yes } & \square \text { No } \\ \square \text { Yes } & \square \text { No } \\ \square \text { Yes } & \square \text { No } \\ \square \text { Yes } & \square \text { No } \\ \square \text { Yes } & \square \text { No }\end{array}$

\section{Case history and social situation}

- Case history. Focus on changes, e.g., worsening

- Development of psychiatric symptoms over time

- Duration of condition/chronic state

- Concrete information on any episodes of violence

- Concrete information on former suicidal risk

- Psychosocial situation (economics, employment, residence, social network activities)

\section{Present state and results}

A. Function, symptoms and limitations

- Present problem, present mental status

- Level of function: present level, loss and duration of the loss

- Present state of symptoms and duration of the symptoms

B. Somatic health

- Somatic health and diseases

- Other important conditions - comorbidity

C. Test results

- When symptoms of depression: MADRS (Montgomery-Åsberg Depression Rating Scale)

D. Medications

- Updated medication record

- Side effects experienced from medications

Past and on-going treatment efforts, involved professional network

A. Tested interventions with assessment of the effect

- What has the referring doctor tried so far?

B. Existing interventions/involved services with assessment of the effect

- Other supportive services that the patient or the family uses

C. Existing plans

\section{The patient's assessment}

- The patient's experience of the situation/problems

- The patient's desire for and motivation for treatment

- The patient's thoughts or attitude towards the treatment intervention

- Has the patient induced self-treatment or complimentary medicine?

Reason for the referral

- «Order»/goal for the referral, what the referring doctor is asking of the specialist health care provider

- Reason for referral at this time

Figure 2 Suggested content of referral letters to specialised mental health care. 
assessment of important referral letter content. We argue that the results of this study are generalisable to health care systems similar to that of Norway. The method that we used to define the recommended content of referral letters, however, we argue is generalisable to health care in general.

There are many similarities between our findings, the Norwegian guideline "The good referral letter" [17], and international suggested standards within somatic care $[5,24]$. However, our study suggests more emphasis on the professional network, in which specialised health care is only one element. For instance, our informants thought information about services and interventions that the patient receives and about the overall care plan are important health care elements to convey when referring a patient to specialised mental health care. "The good referral letter" and other existing referral letter forms within somatic care do lend weak support also for our results concerning patient involvement [4,24], though some include information on the patient's experience with the disease [6]. In contrast, the study on referral letters within mental health by Shaw and colleagues supports our patient focus findings [18]. The specific need for information regarding integrated care and patient involvement for patients with mental disorders highlights the need for a separate guideline for the content of referral letters within mental health care. However, it is noteworthy that similar information requirements have been found in other groups of patients who require shared or integrated care, such as the elderly [4]. Thorsen and colleagues defined three types of referral letters: a request for a specific assessment or treatment, an invitation to have a second opinion, and a request for mutual responsibility for the care of a patient [25]. Care for people that are referred to specialist mental health care usually requires cooperation between this service and primary health care [2]. Referral letters for these patients are therefore often a request for mutual responsibility for a period of time. Further research should explore if our results are valid for patients that are in need of integrated or shared care regardless of the diagnosis.

Optimal prioritisation of patients to ensure sufficient accessibility to specialised mental health care is important to patient safety. However, the structures and processes involved to support this are complex [26]. The present study focuses on one part expected to be relevant; the need for sufficient information to prioritise among patients. It suggests that there is some information seen as important when referring a patient to mental health care not emphasised in a general referral letter form. However, factors other than the content of referral letters can affect the setting of priorities, such as acquaintance with the referring GP [27]. Recognising that there may be many factors affecting the accessibility of specialised mental health care, the present study should be seen as one step in exploring best practices for one of the factors. Future research should emphasise exploration of the referral process in the following areas: (a) if or to what degree the content of referral letters have an impact on the quality of care [28] for patients with mental diseases; (b) the generalisability of our findings to other patient groups and context; and (c) if or to what degree other factors than the content of referral letters are relevant for the outcome of the referral process and the subsequent care for the patient.

\section{Conclusion}

In this study, we have explored the information that a referral letter to specialised mental health should include. We have revealed some important elements of patient information and care that are not aspects of general referral letter forms. Our findings recommend a stronger focus on the on-going and planned care, so that specialised mental health care has a greater understanding of its role, and more emphasis on the patient's assessment and preferences. Beyond that, a general form, like "The good referral letter", can serve as a guideline. The recommended set of introductory check-off points can serve as a checklist for GPs when writing a referral letter and can outline essential information for specialists. However, it is important to evaluate if or to what degree high quality referral letters, according to the results of this study, improve the outcomes for patients and the organisation, and if they have a positive impact on the accessibility of specialised health care for the patients most in need.

\section{Competing interest}

No competing interests are declared for any of the authors.

\section{Authors' contributions}

$\mathrm{MH}$ defined the protocol for the study, observed during the interviews, participated in the analysis of the data and drafted the manuscript. OT took part in the analysis. EB conducted the interviews, while KV made contributions to the development of the protocol together with $B C$. AA supervised and made important contributions during the study process. All authors have contributed during the writing and publishing process, and have approved the final manuscript.

\section{Acknowledgements}

We wish to thank the patient organisation "Mental Helse" for the valuable advice they gave us during the planning of the study and their assistance with the inclusion of patient representatives. In addition, we would like to thank the local Praksiskonsulentordningen (PKO, Practice Consultant System) for their help with participant inclusion. We extend our gratitude to

Oddbjørn Hove, psychologist and researcher, for his important contribution to the analysis of the results.

\section{Source of funding}

Research Network on Integrated Health Care in Western Norway, Helse Fonna HF, Haugesund, Norway.

\section{Author details}

${ }^{1}$ Research Network on Integrated Health Care in Western Norway, Helse Fonna HF, Valen Hospital, N-5451, Haugesund, Valen, Norway. ${ }^{2}$ Department of Public Health and Primary Health Care, Faculty of Medicine and Dentistry, 
University of Bergen, Bergen, Norway. ${ }^{3}$ Section of Mental Health Research, Helse Fonna HF, Haugesund, Norway. ${ }^{4}$ School of Public Health, KU Leuven, University of Leuven, Leuven, Belgium. ${ }^{5}$ Uni Rokkan Centre, Bergen, Norway. ${ }^{6}$ Department of Radiology, Haukeland University Hospital, Bergen, Norway. ${ }^{7}$ Institute of Surgical Sciences, Faculty of Medicine and Dentistry, University of Bergen, Bergen, Norway.

Received: 16 January 2013 Accepted: 15 August 2013

Published: 19 August 2013

\section{References}

1. World Health Organisation: The global burden of disease 2004 Update. Geneva: WHO; 2008. http://www.who.int/healthinfo/global_burden_disease/ GBD_report_2004update_full.pdf.

2. Onyett S: Case management in mental health. California: Chapman \& Hall; 1992

3. Evans $E$, Aiking $H$, Edward $A$ : Reducing variation in general practitioner referral rates through clinical engagement and peer review of referrals: a service improvement project. Qual Prim Care 2011, 19:263-72.

4. Garasen $\mathrm{H}$, Johnsen $\mathrm{R}$ : The quality of communication about older patients between hospital physicians and general practitioners: a panel study assessment. BMC Health Serv Res 2007, 7:133.

5. Grol R, Rooijackers-Lemmers N, Van Kaathoven L, Wollersheim H, Mokkink H: Communication at the interface: do better referral letters produce better consultant replies? Br J Gen Pract 2003, 53(488):217-219.

6. Rubak SL, Mainz J: Kommunikation mellem alment praktiserende laeger og sygehuse. [Communication between general practitioners and hospitals]. Ugeskr laeger 2000, 162(5):648-53.

7. Jiwa M, Satvinder D: Referral writer: preliminary evidence for the value of comprehensive referral letters. Qual Prim Care 2012, 20:39-45.

8. Holman PA, Ruud T, Grepperud S: Horizontal equity and mental health care: a study of priority ratings by clinicians and teams at outpatient clinics. BMC Health Serv Res 2012, 12:162.

9. Øvretveit J: Quality Health Services. Oxford: Blackwell Scientific Press; 1998

10. Kvamme OJ, Olesen F, Samuelson M: Improving the interface between primary and secondary care: a statement from the European Working Party on Quality in Family Practice (EQuiP). Qual Health Care 2001, 10(1):33-9.

11. Berendsen AJ, Kuiken A, Benneker WH, Schuling J, Voom TB, Meyboom-de Jong $B$ : How do general practitioners and specialists value their mutual communication? A survey. BMC Health Serv Res 2009, 9:143.

12. Kada S, Nygaard HA, Geitung JT, Mukesh BN, Naik M, Wold G, Soevik DH: Quality and appropriateness of referrals for dementia patients. Qual Prim Care 2007, 15(1):53-57.

13. Grol R, Wensing M, Eccles M: Improving Patient Care The Implementation of change in Clinical Practice. London: Elsevier Butterworth Heinemann; 2005.

14. Stille CJ, Mazor KM, Meterko V, Wasserman RC: Development and validation of a tool to improve paediatric referral/consultation communication. BMJ Qual Saf 2011, 20(8):692-7.

15. Lovdata: Pasientrettighetsloven 1999-07-02 nr 63, The Act of Patients Right http://www.lovdata.no/all/hl-19990702-063.html.

16. Lovdata: FOR 2000-12-01 nr 1208 Forskrift om prioritering av helsetjenester (Regulation of priority of patients in health care). http://www.lovdata.no/for/ sf/ho/xo-20001201-1208.html.

17. Ree AO: Medisinsk-faglig innhold i henvisninger. Trondheim: KITH: Den gode henvisning; 2003. http://www.kith.no/upload/1121/R2203HenvisningMedisinskFagliglnnhold-v1_1.pdf.

18. Shaw I, Smith KMC, Middleton H, Woodward L: A letter of consequence: referral letters from general practitioners to secondary mental health services. Qual Health Res 2005, 15(1):116-28.

19. Hartveit M, Biringer E, Vanhaeht K, Haug K, Aslaksen A: The Western Norway mental health interface study: a controlled intervention trial on referral letters between Primary Care and Specialist Mental Health Care. BMC Psychiatry 2011, 11(1):177.

20. Bowling A: Research Methods in Health, investigating health and health services. 3rd edition. Berkshire, England: Open University Press Mac Graw Hill; 2009.

21. World Medical Association Declaration of Helsinki: Ethical Principles for Medical Research Involving Human Subjects. http://www.wma.net/en/ 30publications/10policies/b3/.

22. Deneckere S, Robyns N, Vanhaecht K, Euwema M, Panella M, Lodewijckx C, et al: Indicators for follow-up of multidisciplinary teamwork in care processes: results of an international expert panel. Eval Health Prof 2011, 34(3):258-77. Epub 2010/12/31.
23. Hubble M, Duncan B, Miller S: The heart and soul of change. What works in Therapy. Washington: Association AP, editorial; 1999.

24. Newton J, Eccles M, Hutchinson A: Communication between general practitioners and consultants: what should their letters contain? BMJ 1992, 304:821-4.

25. Thorsen O, Hartveit M, Bærheim A: General practitioners' reflections on referring an asymmetric or non-dialogical process? Scand J Prim Health Care. in press.

26. Craig P, Dieppe P, Mcintyre S, Michie S, Nazareth I, Petticrew M: Developing and evaluating complex interventions: The new Medical Research Council guidance. BMJ 2008, 337:a1655.

27. Chew-Graham C, Slade M, Montana C, Stewart M, Gask L: A qualitative study of referral to community mental health teams in the UK: exploring the rhetoric and the reality. BMC Health Serv Res 2007, 7:117.

28. World Health Organisation: Quality of Care A process for making strategic choices in health systems. Geneva: WHO; 2006. http://www.who.int/ management/quality/assurance/QualityCare_B.Def.pdf.

doi:10.1186/1472-6963-13-329

Cite this article as: Hartveit et al: Recommended content of referral letters from general practitioners to specialised mental health care: a qualitative multi-perspective study. BMC Health Services Research 2013 13:329.

\section{Submit your next manuscript to BioMed Central and take full advantage of:}

- Convenient online submission

- Thorough peer review

- No space constraints or color figure charges

- Immediate publication on acceptance

- Inclusion in PubMed, CAS, Scopus and Google Scholar

- Research which is freely available for redistribution

Submit your manuscript at www.biomedcentral.com/submit
Biomed Central 